\title{
Molecular Basis of Subtotal Complement C6 Deficiency A Carboxy-terminally Truncated but Functionally Active C6
}

\author{
Reinhard Würzner, Michael J. Hobart, Barbara A. Fernie, Devesh Mewar, Paul C. Potter,* \\ Ann Orren, and Peter J. Lachmann \\ Molecular Immunopathology Unit, Medical Research Council Centre, Cambridge, United Kingdom; and *Department of Clinical \\ Science \& Immunology, University of Cape Town Medical School, Cape Town, South Africa
}

\begin{abstract}
Individuals with subtotal complement $\mathrm{C} 6$ deficiency possess a C6 molecule that is $14 \%$ shorter than normal C6 and present in low but detectable concentrations (1-2\% of the normal mean). We now show that this dysmorphic $\mathrm{C6}$ is bactericidally active and lacks an epitope that was mapped to the most carboxy-terminal part of C6 using C6 cDNA fragments expressed as fusion proteins in the pUEX expression system. We thus predicted that the abnormal C6 molecule might be carboxy-terminally truncated and sought a mutation in an area $\sim 14 \%$ from the carboxy-terminal end of the coding sequence. By sequencing PCR-amplified products from this region, we found, in three individuals from two families, a mutation that might plausibly be responsible for the defect. All three have an abnormal 5' splice donor site of intron 15, which would probably prevent splicing. An in-frame stop codon is found 17 codons downstream from the intron boundary, which would lead to a truncated polypeptide $13.5 \%$ smaller than normal C6. This result was unexpected, as earlier studies mapped the $\mathrm{C} 5 \mathrm{~b}$ binding site, or a putative enzymatic region, to this part of C6. Interestingly, all three subjects were probably heterozygous for both subtotal $\mathrm{C6}$ and complete $\mathrm{C6}$ deficiency. (J. Clin. Invest. 1995. 95:1877-1883.) Key words: antigenic determinants • complement membrane attack complex • immunologic diseases $\cdot$ meningococcal infections $・$ RNA splicing
\end{abstract}

\section{Introduction}

The sixth component of human complement (C6) is part of the terminal complement cascade that is activated via either the classical or the alternative pathways of complement. Following activation, $\mathrm{C} 6$ is incorporated into the terminal complement complex, which, as membrane attack complex, is capable of membrane disruption and cell lysis when formed on the cell membrane $(1,2)$.

Some individuals with inherited C6 deficiency who ap-

Portions of this work were presented at the XV International Complement Workshop in Kyoto, Japan, 26-30 September 1993.

Address correspondence to Reinhard Würzner, Institut für Hygiene, University of Innsbruck, Fritz Pregl Strasse 3, A-6020 Innsbruck, Austria. Dr. Orren's present address is Department of Immunology, University College Hospital, Galway, Ireland.

Received for publication 19 July 1994 and in revised form 10 November 1994.

J. Clin. Invest.

(C) The American Society for Clinical Investigation, Inc.

0021-9738/95/04/1877/07 \$2.00

Volume 95, April 1995, 1877-1883 peared to lack $\mathrm{C} 6$ by conventional hemolytic complement assays were unequivocally shown by a sensitive ELISA to have C6 at a concentration of $1-2 \%$ of the normal mean (3). Their C6 was able to integrate itself into the terminal complement complex (TCC) ${ }^{1}$ upon complement activation (3). It was, furthermore, hemolytically active but structurally abnormal, as it was $14 \%$ smaller than normal C6 (4). This condition has been designated subtotal C6 deficiency (C6SD). In contrast, the majority of C6-deficient individuals investigated by sensitive hemolytic assays and ELISA were found to completely lack C6 functional and antigenic activity $(3,4)$ and have been designated "quantitatively zero C6 deficient" (C6Q0 [4]).

The eight C6SD individuals from four families investigated so far all appear to express the same dysmorphic molecule and thus may well have the same molecular defect. The dysmorphic C6 show the same abnormal isoelectric focusing pattern, a strong indicator of identity (4). The protein is also indistinguishable (4) from that expressed in the two families with combined subtotal deficiency of $\mathrm{C} 6$ and $\mathrm{C7}(5,6)$. Furthermore, in contrast to individuals with C6Q0, C6SD subjects do not appear to be more susceptible to Neisserial infections than the population at large (4).

Even though the molecular bases of other terminal complement deficiencies were investigated only recently (7-9), the characterization of every mutation in the genes responsible for the deficiencies will not necessarily yield fundamental new information. In this instance, however, a dysmorphic molecule that is still functionally active is secreted in measurable amounts. Thus, the determination of the molecular basis of C6SD should yield important ex vivo-derived information about the regions of C6 that appear to be less essential for membrane attack assembly.

Since the mAb WU 6-4 reacted with this $14 \%$ shorter molecule (3), we initially tried to map its epitope in normal C6 using an expression system. A second commercially available $\mathrm{mAb}$ was also used. Epitope mapping was expected to help with excluding gene regions or even with localizing the most likely regions for the mutation to avoid sequencing the whole gene.

\section{Methods}

Individuals. DNA was obtained from three C6SD subjects (from two families) who have been reported previously. The code used to identify the affected subjects refers to their places in their respective family trees as detailed (4). The South African Cape Coloured family A was ascertained because of complement screening of an 11-yr-old child with

1. Abbreviations used in this paper: C6SD, subtotal C6 deficiency; C6Q0, quantitatively zero C6 deficiency; GTB, gelatin-Triton-benzamidine; NHS, normal human serum; TCC, terminal complement complex; YT, yeast tryptone. 
poststreptococcal nephritis. The Cape Coloured family B was ascertained because a child was $\mathrm{C} 6 \mathrm{Q} 0$ and suffered meningococcal infection (B III-1). On screening the C6 in family members, her mother (B II-2) was found to be C6SD (4).

Buffers. PBS: $9 \mathrm{mM}$ phosphate buffer, pH 7.2, containing $140 \mathrm{mM}$ sodium chloride, Tris-boric acid-EDTA, containing $90 \mathrm{mM}$ Tris, 90 $\mathrm{mM}$ boric acid, and $2.5 \mathrm{mM}$ EDTA; PBS-gelatin-Triton-benzamidine (GTB), PBS supplemented with $0.25 \%$ (wt/vol) gelatin, $0.1 \%$ (vol $/ \mathrm{vol}$ ) Triton X-100, and $1 \mathrm{mM}$ benzamidine.

Antibodies. Monospecific polyclonal IgG directed against C6 and $\mathrm{C} 7$ were raised in goats $(\mathrm{GaC} 6, \mathrm{GaC} 7)$ by standard methods $(10)$. The $\mathrm{mAb}$ WU 6-4 was generated in Balb/c mice as detailed (10). Another murine mAb anti-C6 was obtained from Quidel (San Diego, CA) and is termed QaC6. Biotinylation was performed according to standard protocols (11).

C6 ELISA and SDS-PAGE analysis. For the C6 ELISA either WU 6-4 or QaC6 were used as coating antibodies together with biotinylated GaC6 as detection antibody (3). SDS-PAGE analysis of $100 \mathrm{ng}$ purified C6 or C7 (both from Cytotech, San Diego, CA) was performed using both mAbs as described (4).

Assessment of bactericidal activity. Neisseria meningitidis serogroup B organisms were initially grown for $6 \mathrm{~h}$ in Müller-Hinton broth at $37^{\circ} \mathrm{C}$ and at $\sim 150 \mathrm{rpm}$, until they reached log phase. For the killing experiments each tube contained 4.5-9 $\times 10^{4}$ bacteria in HBSS (Oxoid, Basingstoke, UK) with $0.1 \%$ gelatin adjed. Tubes for determining normal C6 bactericidal activity also contained aliquots of normal human serum (NHS) (range $0.02 \mu \mathrm{l}-10 \mu \mathrm{l}$ ) made up to $10 \mu \mathrm{l}$ with human C6Q0 serum. The test samples also contained aliquots of C6SD serum (from subject A II-1) in the range 0.04 $\mu \mathrm{l}-25 \mu \mathrm{l}$ serum diluted in (or added to a minimum of $10 \mu \mathrm{l}$ ) $\mathrm{C} 6 \mathrm{Q} 0$ serum. Samples were made up to $500 \mu \mathrm{l}$ with HBSS gelatin. Controls were as above with $(i)$ no serum added or (ii) $10 \mu \mathrm{l} \mathrm{C6Q0} \mathrm{serum} \mathrm{added.} \mathrm{Samples} \mathrm{were} \mathrm{incubated} \mathrm{at} 37^{\circ} \mathrm{C}$ for $20 \mathrm{~min}$ at $150 \mathrm{rpm}$. Appropriate dilutions from all tubes were made in Müller-Hinton broth and plated on chocolate agar plates. Plates were incubated at $37^{\circ} \mathrm{C}$ in $5 \% \mathrm{CO}_{2}$, and the colonies were counted the following day. Bactericidal killing, relative to the controls with no serum added, was calculated for each tube. The lowest serum dilution producing at least $80 \%$ bactericidal killing was determined. C6 levels in the NHS and the C6SD serum were determined by ELISA, and the difference in molecular weight was taken into account in calculating the number of C6 molecules present. Efficiency of killing of C6SD was calculated as the ratio between the numbers of normal C6 and C6SD molecules producing $80 \%$ bactericidal killing.

Restriction digests and DNA preparations. Restriction endonuclease digests were carried out according to manufacturer's protocols (New England Biolabs, Hitchin, UK) in the buffer supplied with added BSA (New England Biolabs) at a concentration of $100 \mu \mathrm{g} / \mathrm{ml}$. After digestion, reactions were heat-inactivated at $65^{\circ} \mathrm{C}$ for $30 \mathrm{~min}$ where appropriate. Completion of the digest was assessed by electrophoresis of 20-200 ng of the DNA in a 0.8 or $1.6 \%$ high gelling temperature agarose (Gibco BRL, Gaithersburg, MD) Tris-boric acid-EDTA mini submarine gel plus $2 \mu \mathrm{g} / \mathrm{ml}$ ethidium bromide, and run at 50-65 mA.

For preparative purposes 0.8 or $1.6 \%$ low melting point agarose (Gibco BRL) gels were used. The band of interest was excised and DNA was extracted from the molten agarose (12).

Construction of C6 cDNA libraries for epitope mapping. To characterize the epitopes of the mAbs anti-C6, an epitope mapping method was used that was modified from Stanley and Luzio (13) and Stanley and Herz (14) in that a different vector system was used. Briefly, after ligation of C6 cDNA sequences into an appropriate vector followed by transfection of cells and induction of protein synthesis, the recombinant cells were identified by immunological detection.

Three C6 cDNA clones, together representing the entire C6 coding sequence (15), were kindly provided by Dr. R. G. DiScipio (Research Institute of Scripps Clinic, La Jolla, CA): C6-PVX 1099 bp, C6- $\alpha 1748$ $\mathrm{bp}$, and C6- $\beta 627 \mathrm{bp}$. They were excised from their vector (M13mp18) by enzymatic digestion (EcoRI plus Xba I or EcoRI) and purified in low melting point agarose gels. These fragments were end repaired (16), or further digested using restriction enzymes and then end repaired.
The three subtypes of the expression vector pUEX - pUEX 1, 2, and 3 -were used to generate expression in all three reading frames (17). They carry promotors of phage $\lambda$ as well as the c1857 gene encoding a heat-sensitive repressor (17) and enable expression of proteinspecific cDNA as fusion protein with $\beta$-galactosidase. Vector-transformed cells grow at $30^{\circ} \mathrm{C}$ on yeast tryptone (YT) plates containing 50 $\mu \mathrm{g} / \mathrm{ml}$ ampicillin (YT-A). The vectors were kindly donated by Dr. J. P. Luzio (Cambridge University, Cambridge, UK) and prepared from the host Escherichia coli strain MC 1061 (18) by the alkaline lysis method (12). Purified plasmids were cleaved within the polylinker using Smal and dephosphorylated. An approximately twofold molar excess of endrepaired C6 cDNA fragments (1-20 ng) was ligated into $20 \mathrm{ng}$ SmaI cut vector (pUEX 1,2 , or 3 ) overnight at $15^{\circ} \mathrm{C}$ including controls (12).

The host $E$. coli strain MC 1061, which grows in YT medium at $37^{\circ} \mathrm{C}$, was made competent using $\mathrm{CaCl}_{2}$ (12). $200 \mu$ l competent cells were transformed with $10 \mu \mathrm{l}$ ligation reaction, then grown in $250 \mu \mathrm{l}$ YT medium at $30^{\circ} \mathrm{C}$ for $1 \mathrm{~h}$. They were plated onto YT-A plates and grown at $30^{\circ} \mathrm{C}$ overnight. Replicas were made from transformed MC 1061 colonies after overnight incubation by lifting colonies off the plate with nitrocellulose membranes (BA85; Schleicher \& Schüll, Dassel, Germany), which were then put on new YT-A plates. The original master plates were incubated for $6 \mathrm{~h}$ further at $30^{\circ} \mathrm{C}$ and then stored at $4^{\circ} \mathrm{C}$.

Protein synthesis (expression) was induced in the colonies on the nitrocellulose membranes at $42^{\circ} \mathrm{C}$ for $2 \mathrm{~h}$. The colonies were then lysed in $5 \% \mathrm{SDS}$ at $70^{\circ} \mathrm{C}$ for $30 \mathrm{~min}$, and the generated fusion proteins were further fixed to the nitrocellulose by electrotransfer (19). After the blotting, the nitrocellulose membranes were incubated with PBS-GTB in four steps for 10 min each and DNAse treated, and further bacterial debris was removed. Washing steps (with PBS-GTB) were incorporated between each of the following steps.

The membranes were incubated with $100 \mu \mathrm{g}$ biotinylated or unbiotinylated antibody diluted in $10 \mathrm{ml}$ PBS-GTB for at least $2 \mathrm{~h}$ at $4^{\circ} \mathrm{C}$. All antibody preparations were supplemented with $E$. coli protein $(0.5-$ $2 \mathrm{mg} / \mathrm{ml}$; preparation modified from Sambrook et al. [12]) to minimize reaction of antibodies towards the $E$. coli proteins on the nitrocellulose. The blots were developed using streptavidin horseradish peroxidase or horseradish peroxidase-labeled goat anti-mouse IgG (both from DAKO, Glostrup, Denmark), respectively, at 1/500 dilutions (in PBSGTB, for at least $2 \mathrm{~h}$ ) followed by addition of the peroxidase substrate 4-chloro-1-naphtol (Sigma Chemical Co., Poole, UK; $30 \mathrm{mg}$ dissolved in $10 \mathrm{ml}$ methanol, diluted into $50 \mathrm{ml}$ triethanolamine buffered saline) supplemented with $0.01 \%$ ( $\mathrm{vol} / \mathrm{vol}$ ) $\mathrm{H}_{2} \mathrm{O}_{2}$.

Positive colonies were selected from the original master plate. One aliquot of these cells was expressed again. Another aliquot was processed by the alkaline lysis method (12). Enzymatic digestion with NdeI and size determination in agarose gels identified the location of the expressed cDNA fragment. There are two convenient NdeI cleavage sites within the pUEX vectors and none within the coding sequence of C6. NdeI digestion of empty pUEX vector yields two fragments of 6164 bp and $567 \mathrm{bp}$. Digestion of insert-carrying vector gives rise to a fragment that is $567 \mathrm{bp}$ longer than the insert, as the SmaI site within the polylinker is 54 bp carboxy terminal and $513 \mathrm{bp}$ amino terminal of the two NdeI cleavage sites of the pUEX vectors.

PCR and sequencing. Amplification of C6 DNA sequences was performed according to Saiki et al. (20). Two 24-mer oligonucleotides were synthesized by phosphoramidite chemistry using a gene assembler (Pharmacia LKB, Uppsala, Sweden) corresponding to C6 intron sequences (21): \#23a, 5'-CCTTTACCACTGCCTCTTCTCTGA-3', C6Intron 14 , coding sense, $90-76$ bp $5^{\prime}$ from exon 15 and $\# 24,5^{\prime}$-TTAAACAGGGAACTGGGCTGAGAG-3', C6-Intron 15, anticoding sense, 181-105 bp 3' from exon 15. Both oligonucleotides flank convenient EcoRI sites present in introns 14 and 15 . These restriction sites were used to facilitate ease of cloning of the entire exon 15 plus its intron/ exon boundaries.

For PCR amplification a typical reaction mix consisted of $1 \mu \mathrm{M}$ of sense and antisense primers, 10-100 ng template DNA, $200 \mu \mathrm{M}$ dNTPs (Pharmacia LKB), $1 \mu \mathrm{l}$ of Taq polymerase, $5 \mu \mathrm{l}$ Taq polymerase buffer 
supplemented with $\mathrm{Mg}^{++}$(both Promega Biotec, Madison, WI) and double-distilled water to $50 \mu$ l.

The following DNA samples were used as template: $\sim 50-100 \mathrm{ng}$ genomic DNA, from two healthy subjects and three C6SD subjects, prepared according to a method adapted from Jeffreys (22), and, as positive control, $10 \mathrm{ng}$ of the genomic $\lambda$-clone 25 containing the C6specific DNA sequence between the primers \#23a and \#24 (21). DNA was amplified for 32 cycles using a thermocycler (Perkin-Elmer Cetus Instruments, Norwalk, CT) as follows: denaturation at $94^{\circ} \mathrm{C}$ for $1 \mathrm{~min}$, annealing at $56^{\circ} \mathrm{C}$ for $1 \mathrm{~min}$, and extension at $72^{\circ} \mathrm{C}$ for $3 \mathrm{~min}$. In the first cycle denaturation was extended to $3 \mathrm{~min}$.

The amplified products were separated and excised from low melting point agarose gels, cleaved by EcoRI, and ligated into the EcoRI site of M13mp8, and individual clones were sequenced by the dideoxy chain termination method (23). The sequence was read in both directions in a number of independent clones and compared with published cDNA $(15,24)$ or genomic DNA sequences $(21)$.

In some instances the C6 exon 15 PCR product was gel purified and then directly sequenced from both ends using the Circumvent thermal cycle sequencing kit (New England Biolabs) and $\gamma^{32}$ P-labeled primers \#23a and \#24.

\section{Results}

Assessment of bactericidal activity of the C6 from C6SD subjects. The bactericidal experiments were done on two occasions with C6SD serum from subject A II-1. The specific efficiency of bactericidal killing ranged between 0.1 (10\% of normal) and 0.35 (35\% of normal). Serum from a combined C6SD/C7SD subject (5) was also analyzed twice and found to have comparable bactericidal activity, whereas no killing was observed in the C6Q0 serum alone. The range of the efficiencies determined was high because of the very low absolute values of protein concentration and activity, but the results clearly demonstrated that positive bactericidal activity was mediated by the C6SD protein and that the efficiency was reduced compared to normal C6.

Presence of epitopes of mAbs anti-C6 on the C6 from C6SD subjects. In contrast to the ELISA based on WU 6-4, the ELISA using QaC6 as coating antibody in the otherwise identical ELISA setup produced only background optical densities, not only for C6Q0 but also for C6SD samples (Fig. 1). When the optical densities were calculated, the reaction of $\mathrm{QaC} 6$ to the C6 of C6SD samples was $<4 \%$ when compared to WU 6-4. The values for $\mathrm{C} 6 \mathrm{Q} 0$ and $\mathrm{C} 6 \mathrm{SD}$ samples were even indistinguishable in the QaC6 ELISA. This strongly suggests that the epitope of this $\mathrm{mAb}$ is not present on the shorter $\mathrm{C6}$, although it cannot be fully excluded that the epitope is present but that the three-dimensional conformation of the dysmorphic molecule simply prevents access of the mAb to it.

Presence of epitopes of mAbs anti-C6 on normal C6 after SDS-PAGE and immunoblotting. To ascertain whether the C6 epitopes of both mAbs were still available after SDS treatment, purified $\mathrm{C} 6$ or $\mathrm{C} 7$ were subjected to SDS-PAGE followed by immunoblotting. When WU 6-4 or GaC6 were used for detection, two $\mathrm{C} 6$ bands at $98 \mathrm{kD}$ and $69 \mathrm{kD}$ were detected in each of the C6 tracks; QaC6 only reacted with the band at $98 \mathrm{kD}$. No cross-reaction to $\mathrm{C} 7$ was observed.

Mapping of the epitopes of mAbs anti-C6 to different parts of C6. All three end-filled C6 cDNA fragments were ligated into pUEX 1, 2, and 3 and expressed in MC 1061. Using biotinylated $\mathrm{GaC6}$, expressed protein was recognized when the appropriate vectors were used (with a few exceptions): C6- $\alpha-$ or C6- $\beta-$ coded and -expressed proteins were detected in pUEX 3 ,

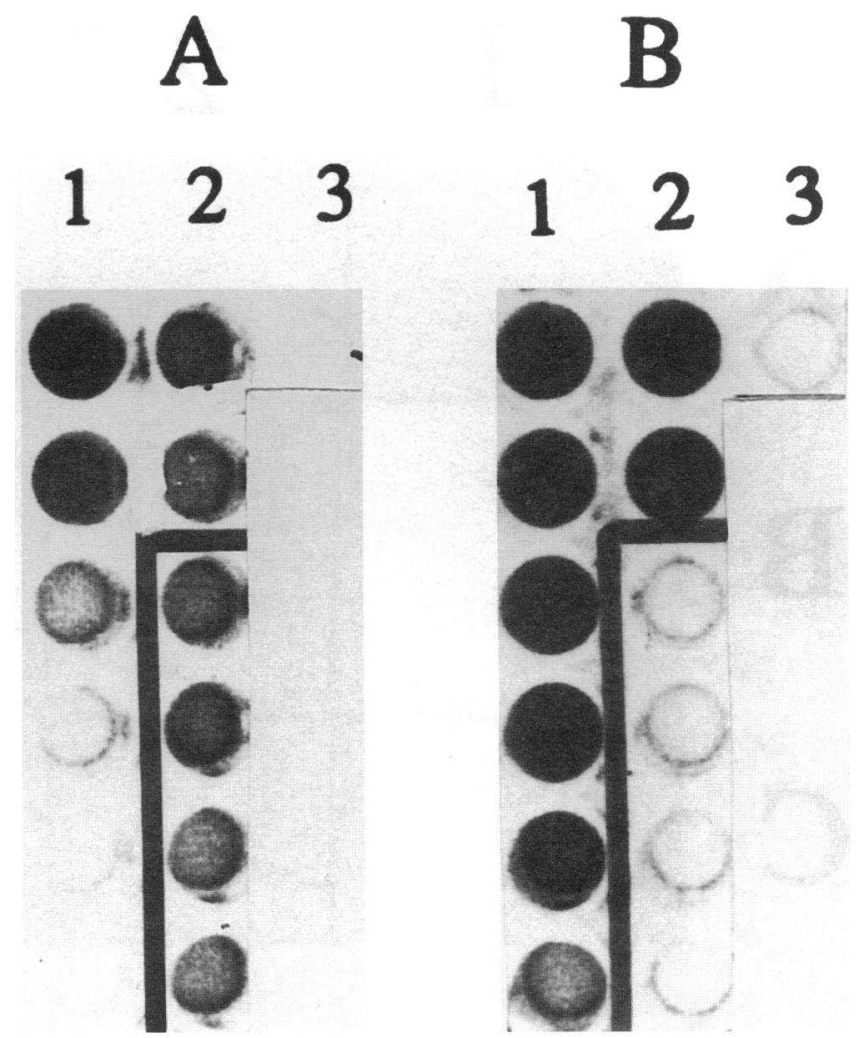

Figure 1. Photograph of the C6 ELISA microtiter plate after development. The left part $(A)$ was coated with WU 6-4 and the right part $(B)$ with QaC6; after coating, both parts were processed in exactly the same way (see Methods). The following samples were assayed from top to bottom (dilution in parentheses): column 1 , NHS $(1 / 80,1 / 160,1 / 320$, $1 / 640,1 / 1280,1 / 2560)$; column 2 , NHS (1/250), NHS (1/250), C6SDWU-01 (1/10), C6SD-RE-01 (1/10), C6SD-B/II-2 (1/10), C6SD-A/II-3 (1/10); column 3, C6Q0 (1/2). A clear and visible substrate turnover was seen in samples from all four C6SD subjects (four families) tested in the ELISA using WU 6-4 as coating antibody. In contrast, no substrate turnover was seen in any of these samples using $\mathrm{QaC6}$ as coating antibody, although this mAb seems to react more strongly with the $\mathrm{C} 6$ of NHS.

whereas C6-PVX-derived proteins were detected in pUEX 1 (more than 50 colonies each). C6 protein-expressing colonies were induced and developed again; a weak staining was observed with the $\mathrm{GaC} 6$ and strong stainings were observed in the combinations QaC6 with C6- $\beta$ and WU 6-4 with C6- $\alpha$ (Fig. 2). Positive colonies were analyzed by alkaline lysis and digestion with NdeI, which confirmed the expected insert sizes.

Mapping of the epitope of QaC6 to the carboxy-terminal end of C6. To map the epitope of QaC6 within C6- $\beta$, aliquots of the latter ( $200 \mathrm{ng}$ each) were digested using three different restriction enzymes: AluI, DdeI, and BspMI (Fig. 3). All three enzymes have only one cleavage site within $\mathrm{C} 6-\beta$, and the resulting two fragments from each digestion were different enough in size to be identified by agarose mini gel electrophoresis. The fragments, however, were not separated from each other before ligation into the pUEX vectors. All three vectors were used for two reasons: First, in the case of DdeI- or BspMIcleaved C6- $\beta$, the amino-terminal fragments need to be expressed in pUEX 3 to allow transcription of a C6 protein, whereas the carboxy-terminal fragments need to be expressed in pUEX 2 or 1 , respectively. Second, this procedure serves as 


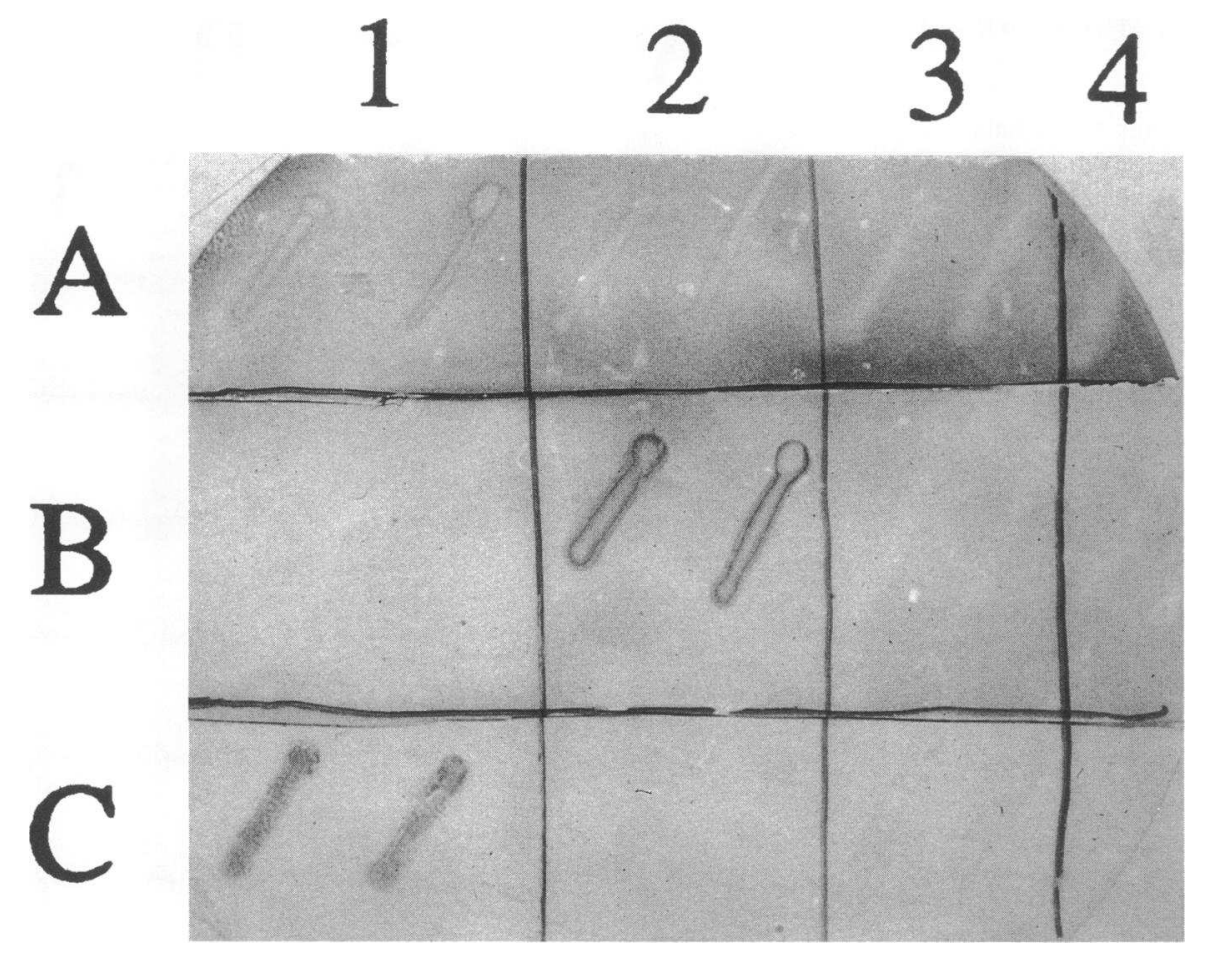

Figure 2. Expression experiments using individual colonies. Transformed colonies from ligations of C6- $\alpha$ (in pUEX 3), C6- $\beta$ (in pUEX 3), or C6-PVX (in pUEX 1) were streaked out and expressed on nitrocellulose in lanes $1-3$, respectively. The selected colonies had previously been identified as expressing a product that was detected by GaC6. A transformed colony that expresses a $C 7$-protein sequence was used as negative control in lane 4 . The strips $A, B$, or $C$ were incubated with biotinylated $\mathrm{GaC6}, \mathrm{QaC6}$, or WU 6-4 (the latter two unbiotinylated), respectively. The epitope of WU 6-4 is in C6$\alpha$ and that of QaC6 in C6- $\beta$. an internal control, as only the predicted vector (pUEX 1, 2, or 3) should allow transcription of a C6-related protein. Thus, the majority of the positive colonies should be found with the predicted vector.

After expression and development using QaC6, most of the positive colonies ( $>95 \%$ ) using AluI-cleaved C6- $\beta$ were in pUEX 3 as expected. The expression of DdeI-cleaved fragments yielded $30 \%$ positive colonies with pUEX 3 , and $61 \%$ positive colonies with pUEX 1, the predicted vector for the carboxyterminal fragment. The expression of BspMI-cleaved C6- $\beta$ yielded $<3 \%$ with pUEX 3 , and $94 \%$ positive colonies with pUEX 1 , the predicted vector for the carboxy-terminal fragment. This carboxy-terminal fragment consists of the 65 most carboxy-terminally located amino acid residues of $\mathrm{C} 6$, amounting to $7 \%$ of the $\mathrm{C} 6$ molecule (Fig. 3).

31 positive colonies (at least 9 for each restriction enzyme) were selected from the plates and expressed again; all were positive with GaC6. 10 of these colonies (at least 3 for each restriction enzyme) were analyzed twice by alkaline lysis and digestion with NdeI. The sizes of the inserts from the positive colonies were within $10 \%$ of the expected sizes for the carboxyterminal fragments. Inserts from 7 GaC6-positive but QaC6negative colonies from the digestion with BspMl were also sized and found to be of the size of the amino-terminal fragment. All inserts were cleaved with the three restriction enzymes, which confirmed that the positive colonies contained the respective carboxy-terminal fragment, whereas the negative colonies contained the respective amino-terminal fragment. Thus, the epitope of QaC6 is most likely present within the most carboxyterminal part of C6.

Characterization of the molecular basis of the subtotal C6 deficiency. While a variety of exotic hypotheses for the molecular basis of the loss of the QaC6 epitope can be put forward, the simplest is that a defect occurs $\sim 14 \%$ from the $\mathrm{COOH}$

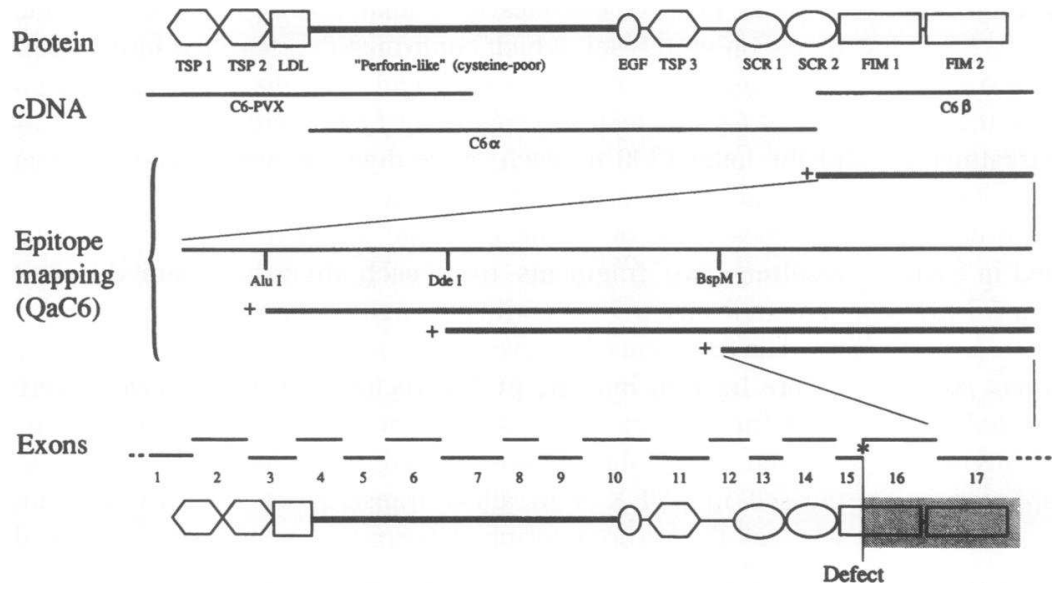

Figure 3. Diagram of the molecular structure of $\mathrm{C} 6$ with epitope mapping data. The domain structure of $\mathrm{C} 6$ consists of the following domains: thrombospondin repeats 1 and 2 (TSP1, TSP2), LDL receptor module (LDL), perforin-like cystein-poor region, epidermal growth factor precursor module (EGF), thrombospondin repeat 3 (TSP3), short consensus repeats 1 and 2 (SCR1, SCR2), and Factor I modules 1 and 2 (FIM1, FIM2), modified from DiScipio and Hugli (15). The location of the C6 cDNA subclones used and the cleavage sites of three restriction enzymes are given, together with epitope mapping data: cDNA fragment-generated proteins recognized by QaC6 ("+") are indicated. The site within C6 at which $86 \%$ of the amino acids are amino terminal and $14 \%$ carboxy terminal (at amino acid residue 785 ) is indicated by an asterisk. The location of the mutation within the molecule and the nontranslated part of C6 are also depicted. 
Table I. Sequencing of Amplified DNA of C6SD Subjects

\begin{tabular}{llcc}
\hline \multirow{2}{*}{ Subject* $^{*}$} & \multicolumn{2}{c}{ Number of PCR Sequences $^{\ddagger}$} \\
\cline { 3 - 4 } & & Wild type & Mutation $^{*}$ \\
\multirow{3}{*}{ A II-1 } & & $n$ & $n$ \\
& First & 2 & 0 \\
& Second & 3 & 0 \\
A II-3 & Third & 1 & 1 \\
& First & 2 & 2 \\
B II-2 & Second & 4 & 1 \\
& First & 2 & 2 \\
\hline
\end{tabular}

* Identification code for three C6SD subjects as used by Orren et al. (4). ${ }^{\ddagger}$ The number of clones obtained from ${ }^{8}$ up to three separate PCR amplifications showing wild type or mutation are detailed.

terminus. This corresponds in the gene to the region of the small exon 15 , which is closely flanked by EcoRI sites (21, Fig. 3).

Amplification of exon 15 sequence was performed by PCR using genomic DNA of two normal subjects and three C6SD subjects (from two unrelated families). A PCR product of appropriate size comparable to the predicted length of $386 \mathrm{bp}$ was detected after amplification of DNA in all cases. The EcoRI digested product, which covers $88.5 \%$ of the sequence between both primers, was also comparable to the predicted length of 299 bp.

EcoRI fragment-derived sequence was obtained from 10 informative clones from the two $\mathrm{C} 6$ normal subjects and from 20 informative clones derived from the three C6SD subjects. All sequences from the clones of the former but only 14 from the clones of the latter were identical (Table I) to the published C6 genomic sequence (21). The other 6 sequences (at least 1 for each subject or 2 for each family) were identical among themselves and showed a mutation at the $5^{\prime}$ splice donor site of intron 15, changing the sequence from AG/gt to AG/gc (Fig. 4). Uncleaved PCR product-derived sequences obtained from a C6SD subject by thermal cycle sequencing also yielded both wild-type sequence and $5^{\prime}$ splice donor mutation. This mutation was the only difference from the wild-type sequence and was found in the area predicted from results obtained at the protein level.

A PCR product from the completely C6-deficient subject, who is the son (B III-3) of one of the C6SD subjects (B II-1), was also sequenced directly by thermal cycle sequencing in both directions. Both sequences were entirely of wild type, suggesting that the $\mathrm{C} 6 \mathrm{Q} 0$ defect lies elsewhere.

\section{Discussion}

The molecular pathologies responsible for complete deficiencies of C6 have not been reported, and those responsible for subtotal deficiency of $\mathrm{C6}$, either alone or in combination with subtotal C7 deficiency, have been investigated in parallel and reported in abstract only $(25,26)$. Both types of deficiencies were pre-viously expected to be caused by a point mutation or other small defect rather than a deletion, as Southern blot analyses of DNA from a number of C6-deficient subjects, including those later characterized as $\mathrm{C6SD}$, have shown normal-sized fragments (27).

To avoid sequencing the whole genomic DNA of subtotal
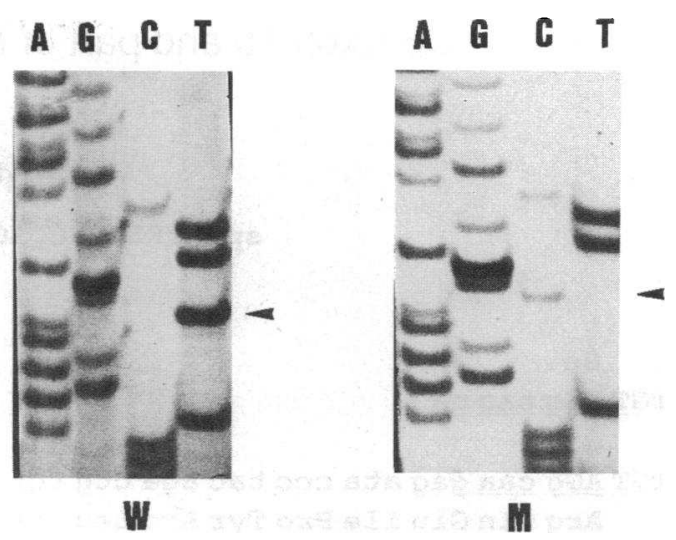

Figure 4. Representative sequencing gel from a C6SD subject $\left(3^{\prime}->5^{\prime}\right.$ orientation). Amplified DNA clones from normal individuals always showed the wild type $(W)$, whereas in clones from C6SD subjects both wild type $(W)$ and a mutated form $(M)$ were detected (see Table I). The sequence depicted is from parts of exon 15 and intron 15 (21): AGAAGAAGACTGTAG/ g taagagataccc; wild type: AG/gt.

C6-deficient subjects, we sought some preliminary information about the location of the defect by mapping the epitopes of two mAbs, one of which was previously shown to react with the abnormal C6 (3). Using the pUEX expression system, the epitope of this mAb (WU 6-4) was mapped within the middle of the coding region of $\mathrm{C6}$. In contrast, QaC6 failed to bind to the dysmorphic C6, implying that its epitope might be missing in the dysmorphic molecule. Its epitope was mapped to the most carboxy-terminal $7 \%$ of the C6 coding sequence. As the dysmorphic molecule is $14 \%$ shorter than normal $\mathrm{C} 6$, we concluded that the C6 of C6SD subjects is very probably carboxy-terminally truncated by $14 \%$. This is supported by SDS-PAGE data, because the lower $\mathrm{C} 6$ band at $69 \mathrm{kD}$ that was not detected by QaC6 possibly represents the $70 \mathrm{kD}$ tryptic cleavage product of C6, consisting of the amino-terminal two-thirds of C6 $(15,24)$.

The molecular basis of C6SD was therefore sought in a region at which $86 \%$ of amino acid residues were amino terminal and $14 \%$ carboxy terminal. Analysis of sequencing data obtained from three subtotal C6-deficient subjects revealed a mutation at the $5^{\prime}$ splice donor site of intron 15 . This mutation was found in all three subtotal C6-deficient subjects but only in 6 out of 20 of their clones, which can be explained by the heterozygosity of these subjects. This was confirmed by Circumvent thermal cycle sequencing (New England Biolabs). Previously, it had been shown that one of these subjects (B II-2), although subtotal C6 deficient, has two complete C6-deficient offspring, indicating that she carries a $C 6 Q O$ gene in addition to the C6SD gene (4). The finding that the $\mathrm{C} 6 \mathrm{Q} 0$ offspring was homozygous for the wild type indicates that the normal sequence data detected in the C6SD subject were obtained from the DNA strand containing the $C 6 Q 0$ gene, which presumably has a mutation in a different area. Recent data indicate that the two types of $\mathrm{C} 6$ deficiency occur on different haplotype backgrounds $(28,29)$. Heterozygosity for two different types of C6 deficiency also seemed likely for the other two subjects (A II-1 and A II-3) investigated (28, depicted as members of family 2 in that publication).

The mutation found would very probably prevent splicing out of intron 15 (30). Intronic sequences would thus be translated, creating one codon altered at the boundary and 17 novel amino acids up to a termination codon in phase with the reading 
Table II. C6 Exon 15 and part of Intron 15 in normals and C6SD subjects

\author{
Wild Type exon 15 \\ SPTLTKLKGBCQLGQKQSGSECICMSPEEDCSE.
}

\begin{abstract}
Normal Sex
Boundary TGT AGg taa ga

1

Consensus TGT AGg cae gag ata ccc tac aga ctg tgt ctg gaa aat ggg aaa acc agt cta gtg taa . . . ?poly A deficient Arg GIn Glu Ile Pro Tyx Arg Leu Cys Leu Glu Ile Gly Lys Thr Ser Leu Val *ᄎ*
\end{abstract}

17 new amino acids coded in intron 15 , boundary amino acid altered

140 amino acids deleted, plus $1 \mathrm{CHO}$ attachment site

$13.5 \%$ shorter polypeptide

frame, 53 nucleotides into intron 15 . This would result in a carboxy-terminally truncated molecule of 790 amino acids, a calculated (from the number of amino acids) $13.5 \%$ shorter than normal C6 (Table II). It can thus very probably account for the phenotypic appearance of the C6 in C6SD.

Assuming that the mutation behaves as predicted and that the lack of reactivity with $\mathrm{QaC6}$ is due to premature termination of the polypeptide, the lack of the carboxy-terminal one-seventh of the $\mathbf{C 6}$ molecule still permits functional activity. The missing part, which corresponds to the carboxy-terminal third of the first Factor I module and the entire second Factor I module of C6 $(15,24)$, has to be considered to be of apparently minor functional importance for TCC assembly. However, these modules have been thought to be responsible for binding to $\mathrm{C} 5$ when in vitro binding studies were performed (31). Other investigators stressed the importance of the short consensus repeats (SCRs) for binding of C6 to C5 $(24,32)$, as SCRs have also been shown to bind specifically to the $\mathrm{C} 5 \mathrm{~b}$ homologues $\mathrm{C} 3 \mathrm{~b}$ and C4b (33), suggesting an evolutionarily conserved mechanism.

Nakano et al. (32) claimed the existence of an enzymatic moiety of $\mathrm{C} 6$ and mapped it to the two serine-rich sequences of the complement control Factor I module 2 of C6. Any such moiety will be lost in the functionally active C6 of C6SD subjects and thus is unlikely be of importance for hemolytic activity.

The question of whether or not the C6 concentration and its functional potency have any significant impact on host defense arises. It seems likely that they do since a local enrichment should be achievable $(34,35)$, only small amounts of complement are needed for marked hemolytic activity $(3,36)$, and sublytic concentrations of complement exert a wide range of important biological functions (37).

However, the degree of specific activity of the C6 found in C6SD is difficult to assess. A sensitive functional assay is the determination of the percentage of incorporation of $\mathrm{C} 6$ into the TCC after complement activation, which at $68 \%$ was not much less than that found in normals $(79.9 \%)$ (3). The relatively high concentration of TCC in nonactivated samples (as much as 5\% of that of normal subjects) may be explained by the spontaneous turnover rate (calculated in healthy animals by Hugo et al. [38]), which may use up a higher percentage of the C6 pool in C6SD subjects. The increase of TCC after complement activation is therefore less pronounced without necessarily implying that this C6 is less active.

We have previously demonstrated the hemolytic activity of the C6SD protein (4), and we now report the use of a sensitive assay that showed that the protein is also bactericidally active, although it is less efficient than normal C6. Bactericidal activity was not detected in another C6SD in a previous report (3), possibly because of the much higher concentration of bacteria (E. coli) used, which could mask functional C6SD activity. Demonstrating bactericidal activity against gram-negative bacteria is important not only because it is clinically relevant, but also because the process is more complex than the production of hemolysis (39). Thus, it can be concluded that the abnormal C6 is only slightly less functionally active than normal C6 (less than an order of magnitude). In addition, the only moderately impaired functional activity implies that the carboxy-terminal part of C6 cannot represent the C5b binding site.

None of the C6SD subjects reported here have suffered Neisserial disease, and there is no evidence that they are any more susceptible than C6-sufficient subjects. Some come from families in which family members who are totally C6 deficient were ascertained by their history of meningococcal infection. Thus, we may assume that the C6SD subjects in these families were exposed to meningococci but did not become ill, perhaps because their very small amount of $\mathrm{C} 6$ protected them. If this assumption is true, C6SD subjects will be less likely to be identified than $\mathrm{C} 6 \mathrm{Q} 0$ patients, who were ascertained because of meningococcal disease either in themselves or in a sibling $(40,41)$.

Both C6 and C7 allotyping have proven to be useful for tracing of carriers in families with affected subjects (42), as the structural genes for $C 6$ and $C 7$ are linked $(43,44)$. These assays may now be complemented by molecular markers that are able to detect the mutation itself, not only in suspected family members but also in the population at large. This will facilitate further investigations into the susceptibility of C6SD subjects to disease.

In summary, the probable molecular basis of the subtotal 
C6 deficiency has been determined, as a plausible mutation was found in an area predicted from SDS-PAGE molecular weight estimation and $\mathrm{mAb}$ epitope mapping. The translated molecule, present in low amounts, was characterized as carboxy-terminally truncated but functionally active, which is surprising as the missing region was thought to be important for functional activity.

\section{Acknowledgments}

We are grateful to Dr. R. G. DiScipio and Dr. J. P. Luzio for their scientific advice and help, and for donating the C6 cDNA clones and providing the pUEX vectors, respectively. We thank Professor H. Waldmann (Oxford University, Oxford, UK) and Dr. B. P. Morgan (University of Wales, Cardiff, UK) for their detailed and critical comments on the data.

Part of this work was supported by the Deutsche Akademische Austauschdienst and the Arthritis and Rheumatism Council (R. Würzner) as well as the Meningitis Trust (A. Orren).

\section{References}

1. Müller-Eberhard, H. J. 1986. The membrane attack complex of complement. Annu. Rev. Immunol. 4:503-528.

2. Esser, A. F., and J. M. Sodetz. 1988. Membrane attack complex proteins C5b-6, C7, C8, and C9 of human complement. Methods Enzymol. 162:551-578.

3. Würzner, R., A. Orren, P. Potter, B. P. Morgan, D. Ponard, P. Späth, M Brai, M. Schulze, L. Happe, and O. Götze. 1991. Functionally active complement proteins $\mathrm{C} 6$ and $\mathrm{C} 7$ detected in C6- or C7-deficient individuals. Clin. Exp. Immunol. 83:430-437.

4. Orren, A., R. Würzner, P. C. Potter, B. A. Fernie, S. Coetzee, B. P. Morgan, and P. J. Lachmann. 1992. Properties of a low molecular weight complement component $\mathrm{C} 6$ found in human subjects with subtotal C6 deficiency. Immunology. 75:10-16.

5. Lachmann, P. J., M. J. Hobart, and P. Woo. 1978. Combined genetic deficiency of C6 and C7 in man. Clin. Exp. Immunol. 33:193-203.

6. Morgan, B. P., J. P. Vora, A. J. Bennett, J. P. Thomas, and N. Matthews. 1989. A case of hereditary combined deficiency of complement components C6 and C7 in man. Clin. Exp. Immunol. 75:396-401.

7. Wang, X., D. T. Fleischer, G. Peter, W. T. Whitehead, D. L. Haviland, and R. A. Wetsel. 1993. Human C5 deficiency: a nonsense mutation in the first codon of the $\beta$-chain. Mol. Immunol. 30(Suppl. 1):61. (Abstr.)

8. Kaufmann, T., G. M. Hänsch, C. Rittner, P. Späth, F. Tedesco, and P. M. Schneider. 1993. Genetic basis of human complement C8 $\beta$ deficiency. J. Immunol. 150:4943-4947.

9. Burrone, O., S. Mancardi, and F. Tedesco. 1993. Molecular characterization of the C $8 \beta$-mRNA from a C8 $\beta$-deficient family. Mol. Immunol. 30(Suppl. 1):4. (Abstr.)

10. Würzner, R., R. Nitze, and O. Götze. 1990. C7*9, a new frequent C7 allele detected by an allotype specific monoclonal antibody. Complement Inflammation. 7:290-297.

11. Guesdon, J. L., T. Ternynck, and S. Avrameas. 1979. The use of avidinbiotin interaction in immunoenzymatic techniques. J. Histochem. Cytochem. 27:1131-1139.

12. Sambrook, J., E. F. Fritsch, and T. Maniatis. 1989. Molecular Cloning: A Laboratory Manual. Cold Spring Harbor Laboratory, Cold Spring Harbor, NY.

13. Stanley, K. K., and J. P. Luzio. 1984. Construction of a new family of high efficiency bacterial expression vectors: identification of cDNA clones coding for human liver proteins. EMBO (Eur. Mol. Biol. Organ.) J. 3:1429-1434.

14. Stanley, K. K., and J. Herz. 1987. Topological mapping of complement component $\mathrm{C} 9$ by recombinant DNA techniques suggests a novel mechanism for its insertion into target membranes. EMBO (Eur. Mol. Biol. Organ.) J. 6:19511957.

15. DiScipio, R. G., and T. E. Hugli. 1989. The molecular architecture of human complement component C6. J. Biol. Chem. 264:16197-16206.

16. Bankier, A. T., K. M. Weston, and B. G. Barrell. 1987. Random cloning and sequencing by the M13/dideoxynucleotide chain termination method. Methods Enzymol. 155:51-93.

17. Bressan, G. M., and K. K. Stanley. 1987. pUEX, a bacterial expression vector related to $\mathrm{pEX}$ with universal host specificity. Nucleic Acids Res. 15:10056

18. Meissner, P. S., W. P. Sisk, and M. L. Berman. 1987. Bacteriophage $\lambda$ cloning system for the construction of directional cDNA libraries. Proc. Natl. Acad. Sci. USA. 84:4171-4175.

19. Towbin, H., T. Staehlin, and J. Gordon. 1979. Electrophoretic transfer of proteins from polyacrylamide gels to nitrocellulose sheets: procedure and some applications. Proc. Natl. Acad. Sci. USA. 76:4350-4354.

20. Saiki, R. K., D. H. Gelfand, S. Stoffer, S. J. Scharf, R. Higuchi, G. T. Horn, K. B. Mullis, and H. A. Erlich. 1988. Primer-directed enzymatic amplification of DNA with thermostable DNA polymerase. Science (Wash. DC). 239:487-491.

21. Hobart, M. J., B. A. Fernie, and R. G. DiScipio. 1993. The structure of the human $\mathrm{C} 6$ gene. Exons and evolution of the terminal complement system: a novel paradigm for mosaic protein. Biochemistry. 32:6198-6205.

22. Jeffreys, A. J. 1979. DNA sequence variants in the $\mathrm{G} \gamma-, \mathrm{A} \gamma-, \delta$ - and $\beta$ globulin genes of man. Cell. 18:1-10.

23. Sanger, F., S. Nicklen, and A. R. Coulson. 1977. DNA sequencing with chain terminating inhibitors. Proc. Natl. Acad. Sci. USA. 74:5463-5467.

24. Haefliger, J. A., J. Tschopp, N. Vial, and D. E. Jenne. 1989. Complete primary structure and functional characterization of the sixth component of the human complement system. Identification of the C5b-binding domain in complement C6. J. Biol. Chem. 264:18041-18051.

25. Hobart, M. J., B. A. Fernie, R. Würzner, B. P. Morgan, and P. J. Lachmann. 1993. Molecular basis of combined C6 and C7 deficiency: C6. Mol. Immunol. 30(Suppl. 1):16. (Abstr.)

26. Würzner, R., D. Mewar, and P. J. Lachmann. 1993. The dysmorphic but functionally active C6 of subtotal C6 deficient subjects is carboxyterminally truncated. Mol. Immunol. 30(Suppl. 1):63. (Abstr.)

27. Hobart, M. J., B. A. Fernie, P. J. Lachmann, B. P. Morgan, A. Orren, and R. G. DiScipio. 1989. C6 and C7 genes in normal and deficient individuals. Complement Inflammation. 6:345. (Abstr.)

28. Potter, P. C., C. Warburton, R. Würzner, A. Orren, and R. G. DiScipio. 1993. Homozygous expression of a 12.5 kilobase allele of the Msp-1 restriction fragment length polymorphism of the $\mathrm{C} 6$ gene in patients with total deficiency of the sixth component of complement. Exp. Clin. Immunogenet. 10:38-44.

29. Fernie, B. A., M. J. Hobart, G. Delbridge, P. C. Potter, A. Orren, and P. J. Lachmann. 1994. C6 haplotypes: associations of a Dde I site polymorphism to complement deficiency genes and the Msp I restriction fragment length polymorphism (RFLP). Clin. Exp. Immunol. 95:351-356.

30. Green, M. R. 1991. Biochemical mechanisms of constitutive and regulated pre-mRNA splicing. Annu. Rev. Cell Biol. 7:559-599.

31. DiScipio, R. G. 1992. Formation and structure of the C5b-7 complex of the lytic pathway of complement. J. Biol. Chem. 267:17087-17094.

32. Nakano, Y., M. Hashimoto, N. H. Choi, Y. Sugita, T. Tobe, T. Mazda, and M. Tomita. 1991. Functional and structural domains of the sixth component (C6) of human complement. Chem. Pharm. Bull. (Tokyo). 39:432-436.

33. Klickstein, L. B., T. J. Bartow, V. Miletic, L. D. Rabson, J. A. Smith, and D. T. Fearon. 1988. Identification of distinct C $3 \mathrm{~b}$ and C4b recognition sites in the human $\mathrm{C} 3 \mathrm{~b} / \mathrm{C} 4 \mathrm{~b}$ receptor (CR 1, CD 35) by deletion mutagenesis. J. Exp. Med. 168:1699-1717.

34. Würzner, R., A. Orren, and P. J. Lachmann. 1992. Inherited deficiencies of the terminal components of human complement. Immunodefic. Rev. 3:123147.

35. Würzner, R., V. C. Joysey, and P. J. Lachmann. 1994. Complement component C7: assessment of in vivo synthesis after liver transplantation reveals that hepatocytes do not synthesize the majority of human C7. J. Immunol. 152:4624-4629.

36. Boyer, J. T., E. P. Gall, M. E. Norman, U. R. Nilsson, and T. S. Zimmerman. 1975. Hereditary deficiency of the seventh component of complement. $J$. Clin. Invest. 56:905-913.

37. Morgan, B. P. 1989. Complement membrane attack on nucleated cells: resistance, recovery and non-lethal effects. Biochem. J. 264:1-14.

38. Hugo, F., C. Berstecher, S. Kramer, W. Fassbender, and S. Bhakdi. 1989. In vivo clearance studies of the terminal fluid-phase complement complex in rabbits. Clin. Exp. Immunol. 77:112-116.

39. MacKay, S. L. D., and J. R. Dankert. 1990. Bactericidal killing and inhibition of inner membrane activity by C5b-9 complexes as a function of the sequential addition of $\mathrm{C} 9$ to C5b-8 sites. J. Immunol. 145:3367-3371.

40. Petersen, B. H., T. J. Lee, R. Snyderman, and G. F. Brooks. 1979. Neisseria meningitidis and Neisseria gonorrhoeae bacteremia associated with $\mathrm{C} 6, \mathrm{C} 7$ or $\mathrm{C} 8$ deficiency. Ann. Intern. Med. 90:917-920.

41. Ross, S. C., and P. Densen. 1984. Complement deficiency status and infection: epidemiology, pathogenesis and consequences of Neisserial and other infections in an immune deficiency. Medicine (Baltimore). 63:243-273.

42. Würzner, R., N. Rance, P. C. Potter, M. L. Hendricks, P. J. Lachmann, and A. Orren. 1992. C7 M/N protein polymorphism typing applied to inherited deficiencies of human complement proteins $\mathrm{C6}$ and $\mathrm{C} 7$. Clin. Exp. Immunol. 89:485-489.

43. Hobart, M. J., V. Joysey, and P. J. Lachmann. 1978. Inherited structural variation and linkage relationships of C7. J. Immunogenet. (Oxf.). 5:157-163.

44. Tokunaga, K., G. Dewald, K. Omoto, and T. Juji. 1986. Family study on the polymorphism of the sixth and seventh components (C6 and C7) of human complement: linkage and haplotype analyses. Am. J. Hum. Genet. 39:414-419. 